\title{
Training Helicopter Selection Based on Analytic Hierarchy Process
}

\author{
Yu Qian ${ }^{1,}$, , Heng-Xing Wang ${ }^{1, b}$ \\ ${ }^{1}$ Civil Aviation Flight University of China, Deyang, Sichuan, China

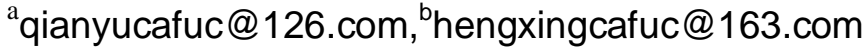

Keywords: Analytic Hierarchy Process; Comprehensive Evaluation; Helicopter Selection.

Abstract. Analytic Hierarchy Process (AHP) is a multi-criteria decision-making method combining qualitative analysis with quantitative analysis. This method can analyze the essence, influencing factors and inherent relations of the problem, so as to construct a hierarchical model and solve problems easily with mathematical thinking. This article first introduces the helicopter selection process, and then applies AHP in the selection and evaluation of the aircraft. Finally, it establishes a hierarchical model of helicopter selection, through which the model can be selected quickly and intuitively to suit its own model.

\section{Introduction}

From the mid-1960s to the present, the operation scope of China's civilian helicopters has been spread throughout the provinces, autonomous regions and municipalities directly under the central government except Taiwan and Tibet autonomous region ${ }^{[1]}$.

Many scholars in China had carried out research on aircraft selection and selection. Chen Zhi-Huai Chen ${ }^{[2]}$ put forward the main content and order of selection evaluation of civil aircraft. De-Jun Liu ${ }^{[3]}$ applied data envelopment analysis to the selection and evaluation of aircraft models. Chuan-Dong $\mathrm{Hu}^{[4]}$ and so on through the market research, domestic 1 to 2-ton light civilian helicopter industry to make recommendations. Zhao-Hui $\mathrm{He}^{[5]}$ applied the principle of fuzzy transformation of fuzzy mathematics to the judgment of purchasing new models.

The price of modern helicopters is very high, and whether the selection is correct or not has great influence on the operation and economic benefits of the company. Therefore, helicopter planning and aircraft selection is one of the most important strategic plans for helicopter purchase units. In this paper, a hierarchical model of helicopter selection is established, and the AHP is used to provide a reference for model selection.

\section{The content and order of helicopter selection evaluation}

When selecting a general aviation enterprise, we need to consider the following three points: first, according to the development needs of our country, our region and our company, we choose the models that are suitable for our domestic and local needs. That is to say, choose the type according to the use. Secondly, the selected aircraft must have the airworthiness certificate approved by the competent airworthiness authorities of the production country and the airworthiness authorities of our country approving the type of the aircraft, or get the airworthiness certificate approved by China Civil Aviation airworthiness authorities, that is to say, the security is better. Thirdly, it is necessary to consider the economy, comfort and maintainability of the purchase and purchase models. In a word, we should choose the model which is safe, reliable, economical, easy to maintain and good service ${ }^{[6]}$.

Helicopter selection generally according to the internal and external factors of airlines and to forecast the market demand of the helicopter operating range is to use, then in accordance with the 
company's primary type selection, flight environment, airport conditions, the primary after the helicopter from the comprehensive analysis of two aspects of economy and technology of certain selected models. The selection process is shown in Figure 1.

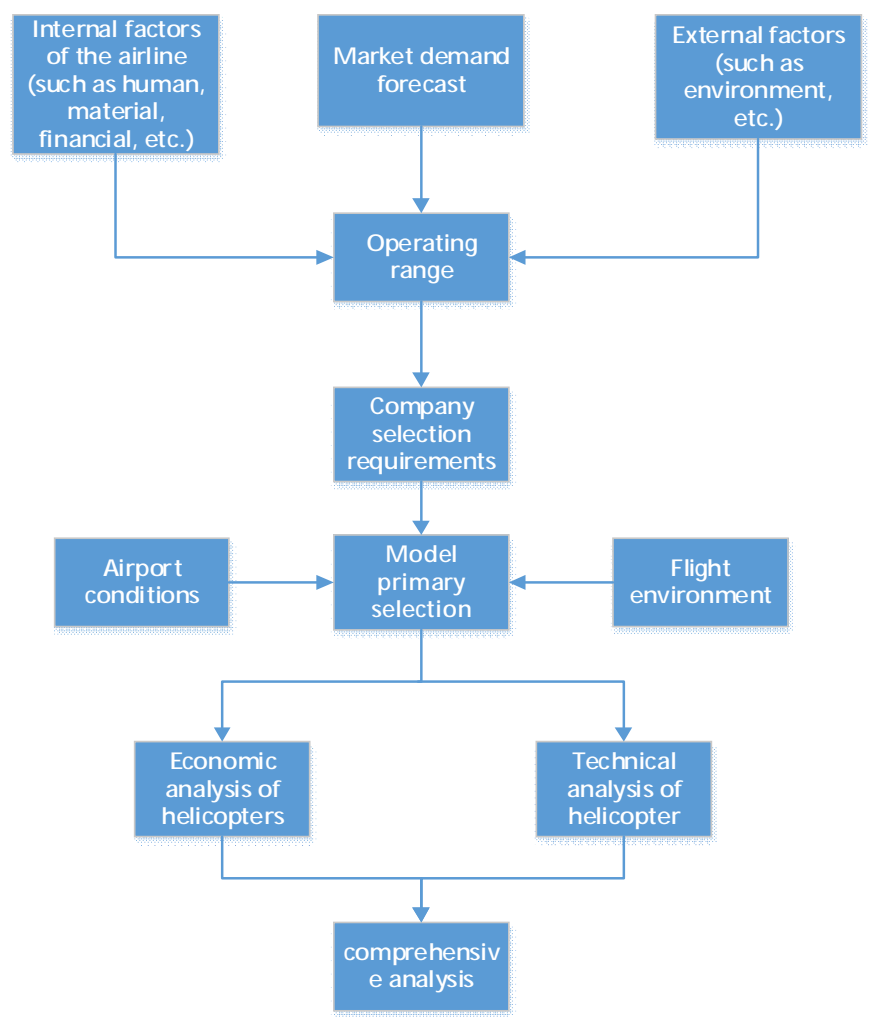

Figure 1 flow chart of helicopter selection

\section{Evaluation of helicopter selection by analytic hierarchy process}

First, we consider the various factors involved in the selection and evaluation of the helicopter, they should be: engine performance, noise characteristics, electronic equipment, airport routes adaptability, adaptability, cabin comfort, fuel utilization, helicopter life and convenient disassembly, purchase cost. We will be involved in the helicopter selection evaluation factors are divided into two categories, namely the related technique of the engine performance and noise characteristics, electronic equipment, airport routes adaptability, adaptability, cabin comfort for a class; related to the economy of the fuel utilization rate, purchase cost, helicopter life, become a kind of convenient disassembly. A hierarchical structure of AHP for helicopter selection is established to solve this problem, as shown in Figure 2.

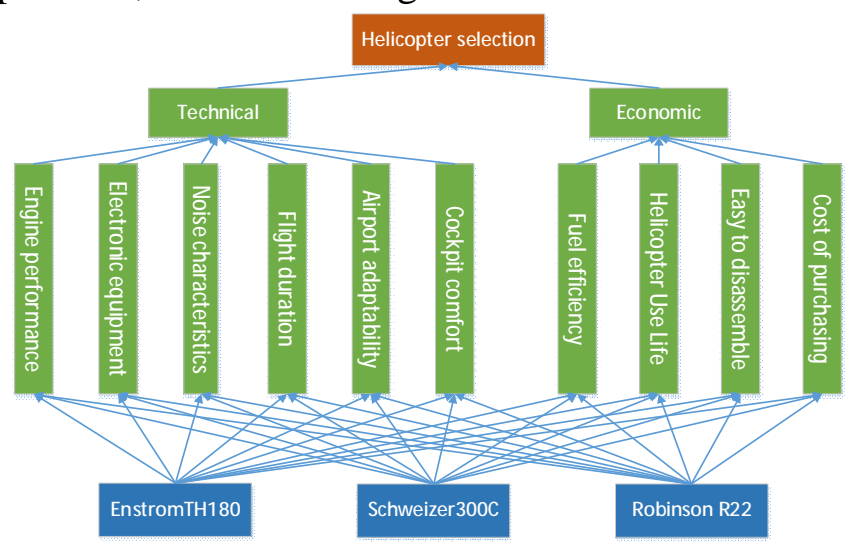

Figure 2 helicopter selection evaluation hierarchy structure 


\section{Numerical Example}

We choose 3 commonly used training helicopters.
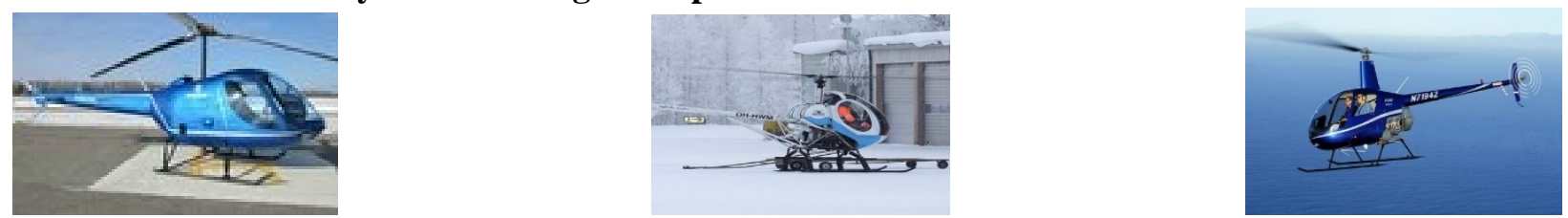

EnstromTH180

Schweizer300C

\section{Robinson R22}

\section{selection evaluation matrix and calculation of importance}

We give a hierarchical figure of helicopter selection evaluation, and we evaluate each level according to the benchmarks and principles of analytic hierarchy process.

First of all, the total target of helicopter selection is to compare the factors of the second layers. The results of the second - layer pairwise comparison matrix and the weight calculation are shown in Table 1.

Table 1: Pairwise comparison of elements of Level 2

\begin{tabular}{|c|c|c|c|}
\hline Helicopter selection & Technical & Economic & Importance \\
\hline Technical & 1 & 0.5 & 0.3333 \\
\hline Economic & 2 & 1 & 0.6667 \\
\hline
\end{tabular}

And then compare the elements under the second stratum

Table 2 Comparison between subprojects under technical subprojects

\begin{tabular}{|c|c|c|c|c|c|c|c|}
\hline Technical & $\begin{array}{c}\text { Engine } \\
\text { performance }\end{array}$ & $\begin{array}{c}\text { Noise } \\
\text { characteristics }\end{array}$ & $\begin{array}{c}\text { Electronic } \\
\text { equipment }\end{array}$ & $\begin{array}{c}\text { Flight } \\
\text { duration }\end{array}$ & $\begin{array}{c}\text { Airport } \\
\text { adaptability }\end{array}$ & $\begin{array}{c}\text { Cockpit } \\
\text { comfort }\end{array}$ & Importance \\
\hline Engine performance & 1 & 1 & 2 & 2 & 2 & 2 & 0.2499 \\
\hline Noise characteristics & 1 & 1 & 0.3333 & 0.5 & 1 & 1 & 0.1168 \\
\hline Electronic equipment & 0.5 & 3 & 1 & 1 & 2 & 2 & 0.2122 \\
\hline Flight duration & 0.5 & 2 & 1 & 1 & 2 & 2 & 0.1984 \\
\hline Airport adaptability & 0.5 & 1 & 0.5 & 0.5 & 1 & 0.5 & 0.1113 \\
\hline Cockpit comfort & 0.5 & 1 & 0.5 & 0.5 & 1 & 1 & 0.1113 \\
\hline
\end{tabular}

Table 3 paired comparison between subitems in economic performance

\begin{tabular}{|c|c|c|c|c|c|}
\hline Economic & Fuel efficiency & $\begin{array}{c}\text { Helicopter Use } \\
\text { Life }\end{array}$ & $\begin{array}{c}\text { Easy to } \\
\text { disassemble }\end{array}$ & $\begin{array}{c}\text { Cost of } \\
\text { purchasing }\end{array}$ & Importance \\
\hline Fuel efficiency & 1 & 1 & 2 & 1 & 0.2857 \\
\hline Helicopter Use Life & 1 & 1 & 2 & 1 & 0.2857 \\
\hline Easy to disassemble & 0.5 & 0.5 & 1 & 0.5 & 0.1429 \\
\hline Cost of purchasing & 1 & 1 & 2 & 1 & 0.2857 \\
\hline
\end{tabular}


Table 4 comprehensive weight of each subproject

\begin{tabular}{|c|c|}
\hline & $\begin{array}{c}\text { Comprehensive } \\
\text { importance }\end{array}$ \\
\hline Engine performance & 0.0833 \\
\hline Noise characteristics & 0.0389 \\
\hline Electronic equipment & 0.0707 \\
\hline Flight duration & 0.0661 \\
\hline Airport adaptability & 0.0371 \\
\hline Cockpit comfort & 0.0371 \\
\hline Fuel efficiency & 0.1905 \\
\hline Helicopter Use Life & 0.1905 \\
\hline Easy to disassemble & 0.0952 \\
\hline Cost of purchasing & 0.1905 \\
\hline
\end{tabular}

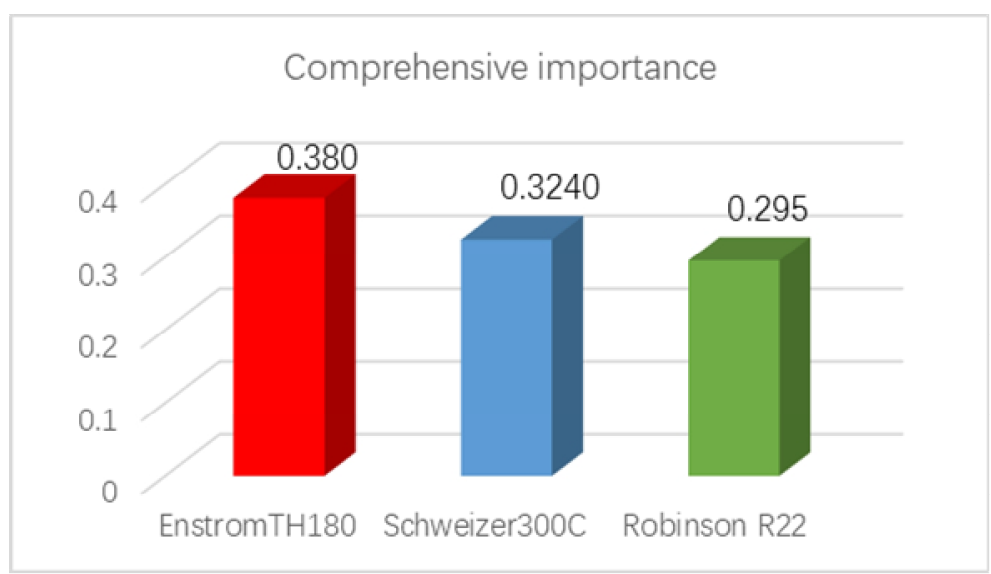

Figure 3 comprehensive weight diagram

According to the comprehensive importance Figure 3, it is clear that the EnstromTH180 model is suitable for the three types of helicopters, so the type selection process is over.

\section{Conclusions}

Entering the 21st century, China's macro economic and social development environment is conducive to the development of general aviation. Higher requirements for helicopter training and teaching are provided, and reasonable helicopter selection is more and more important. Based on AHP, a helicopter selection model is built, which makes the selection work simpler and more intuitive. At the same time, the feasibility of the model is proved by an example, which provides a reference for future helicopter selection.

\section{References}

[1] Ping Meng. General Aviation Aircraft Handbook and selection guide [M]. Beijing: Aeronautical Industry Press, 2007.

[2] Zhi-Huai Chen. Assessment of the selection of civil aircraft [J] civil aviation economy and technology, 1994.6.

[3] De-Jun Liu. Application of DEA in the comprehensive evaluation of civil aircraft models [J]. Journal of CAAC, 1993, 2 (1): 1-9.

[4] Chuan-Dong $\mathrm{Hu}$. Domestic 1 to 2 tons light civil helicopter industry development [J]. helicopter technology, 2009, (160): 62-67.

[5] Zhao-Xi He. Fuzzy evaluation of the type selection of aircraft [J]. Journal of CAAC, 1992, 10 (3): 6-17.

[6] Bing-Jiang Zhang. Analytic hierarchy process and application case [M]. Beijing: Electronic Industry Press, 2014. 